\title{
O FLUXO DE RECURSOS FINANCEIROS PARA O SUS NA MACRORREGIÃO EXTREMO-SUL DO ESTADO DA BAHIA
}

\author{
Júlio Moraes Brito Regis ${ }^{1}$; Thereza Christina Coelho²; Andrei Souza Teles ${ }^{3}$; Milla \\ Pauline da Silva Ferreira ${ }^{4}$; Ilane Moreira Figueredo5 ${ }^{5}$ Guilherme Braga Alencar \\ de Novais'; \\ 1. Bolsista FAPESB, Graduando em Medicina, Universidade Estadual de Feira de Santana, e-mail: \\ jmbreges@hotmail.com \\ 2. Orientadora, Departamento de Saúde, Universidade Estadual de Feira de Santana, e-mail: tcuide@uol.com.br \\ 3. Participante do Núcleo de Saúde Coletiva, Departamento de Saúde, Universidade Estadual de Feira de Santana, e- \\ mail: stdrei@hotmail.com \\ 4. Participante do Núcleo de Saúde Coletiva, Departamento de Saúde, Universidade Estadual de Feira de Santana, e- \\ mail: millapauline@ hotmail.com \\ 5. Participante do Núcleo de Saúde Coletiva, Departamento de Saúde, Universidade Estadual de Feira de Santana, e- \\ mail: ilanemoreira@outlook.com \\ 6. Participante do Núcleo de Saúde Coletiva, Departamento de Saúde, Universidade Estadual de Feira de Santana, e- \\ mail: guilhermea15@ hotmail.com
}

\section{PALAVRAS-CHAVE: RECURSOS FINANCEIROS; ALOCAÇÃO DE RECURSOS; FINANCIAMENTO}

\section{INTRODUÇÃO}

Desde a Conferência Internacional sobre Cuidados Primários em Saúde realizada em Alma-Ata, União Soviética, em 1978, iniciou-se mundialmente um processo de repensar as práticas de saúde. Muitos países da América Latina promoveram reformas de saúde, especialmente durante a segunda metade da década de 90 (MÉDICI, 2005).

Em 1.980, o governo federal participava com $75 \%$ do financiamento público na saúde, e os Estados e Municípios com 25\%. Desde então, e especialmente após novo pacto federativo constitucional de 1.988, os municípios e Estados vêm assumindo suas novas e maiores responsabilidades, e somados, elevaram sua participação de $25 \%$ para $54 \%$ do total do financiamento público da saúde, o mesmo não ocorrendo com a União, cuja participação porcentual caiu de 75\% para 46\% (OLIVEIRA, 2012).

O subfinanciamento é um dos pontos mais frágeis do sistema público de saúde. Isso se deve ao fato do Brasil não gastar o mínimo suficiente e por haver uma tendência de crescimento das necessidades de recursos devido ao crescimento demográfico e a incorporação de novas tecnologias ao processo de diagnóstico e tratamento (COELHO; SCATENA, 2014). Esta situação impossibilita os gestores municipais e estaduais de organizarem a oferta de serviços com qualidade, resultando no insuportável congestionamento nos prontos-socorros e consultórios de especialidades, na impossibilidade da atenção básica "ser a porta de entrada preferencial com alta resolutividade", e na permanência do predomínio de intervenções tardias, doenças preveníveis não prevenidas, doenças agravadas não atendidas precocemente e mortes evitáveis não evitadas. (CONASS, 2011)

Hoje, apesar do conhecimento dos elementos participantes da gestão do SUS, ainda se conhece muito pouco sobre como se efetiva o seu financiamento e como determinadas decisões e escolhas podem influir para o seu funcionamento. Desta forma, torna-se cada vez mais fundamental conhecer como o fluxo das contas municipais se organiza e como se organizam os gastos do SUS e a estrutura de financiamento adotada, com a finalidade de que se possa promover um planejamento mais eficiente, além de uma maior e melhor fiscalização do sistema como um todo.

Tendo em vista a relevância do tema para o entendimento de como o financiamento do SUS, de fato, é realizado e o cenário de subfinanciamento em que o 
SUS está inserido, este estudo objetivou identificar as principais fontes de recursos para os municípios da macrorregião Leste do estado da Bahia e analisar os gastos públicos desses municípios com o SUS entre os anos de 2010 e 2012.

\section{MATERIAL E MÉTODOS OU METODOLOGIA (ou equivalente)}

O modelo de Contas Nacionais de Saúde (National Health Accounts) - NHA, trata-se de uma ferramenta de síntese, descrição e análise das informações financeiras que objetiva melhorar a performance do sistema de saúde. Mensura os gastos em saúde utilizando uma matriz com quatro categorias básicas da atenção à saúde:

1- Fontes de Financiamento: são responsáveis por fornecer as verbas para o setor da saúde, tais como os recursos de arrecadação tributária federal, estadual e municipal;

2- Agentes de Financiamento: são os receptores intermediários das verbas de fontes de financiamento e as usam para pagar serviços de saúde e produtos (medicamentos, remédios, etc);

Estas categorias orientam a montagem das tabelas e guiam, estruturalmente, a análise. A identificação detalhada do fluxo de recursos permite identificar como cada serviço é financiado.

A partir deste modelo foi montada a Tabela 1 (Fontes $\mathrm{X}$ Agentes de Financiamento) utilizando-se do programa Excel para formar matrizes contábeis (receita $\mathrm{X}$ despesas), as quais organizaram os dados (valores) coletados nos sistemas de informação, tais como o Sistema de Informações sobre Orçamentos Públicos de Saúde (SIOPS), o Departamento de Informática do SUS (DATASUS) e o sistema de informação mantido pelo Fundo Nacional de Saúde (FNS), todos disponíveis na internet.

A análise dos dados relativos aos gastos em saúde em suas várias dimensões e relações foi realizada através de operações de natureza contábil, a partir do cálculo das receitas e despesas de cada matriz. Dessa forma, a análise forneceu o ponto de partida para a construção de um sistema de contas em cada município do estado da Bahia.

Em seguida, foi realizado o deflacionamento dos valores para melhor comparação entre os anos estudados, tomando como base o Índice Nacional de Preços ao Consumidor Amplo Especial (IPCA), desenvolvido pelo Instituto Brasileiro de Geografia e Estatística (IBGE). A partir da análise dos dados e tabelas das cidades da macrorregião Leste da Bahia, foi possível identificar as principais fontes de recursos dos municípios e traçou-se um perfil de como os vários tipos de receitas são distribuídas para cada município, cada região de saúde e macrorregião.

\section{RESULTADOS E/OU DISCUSSÃO (ou Análise e discussão dos resultados)}

Após análise criteriosa dos dados coletados, foi possível traçar o perfil do fluxo dos recursos financeiros para os municípios da Macrorregião Leste do Estado da Bahia, no período de 20010 a 2012, bem como analisar a participação das esferas administrativas no financiamento da saúde para cada ano do estudo. Somando-se as participações das esferas federal, estadual e municipal, o montante totalizou um volume real de $\mathrm{R} \$$ 4.855.745.944,03, ou seja, anulando-se o efeito da inflação no período. Em termos nominais o valor total das receitas da macrorregião estudada foi de $\mathrm{R} \$$ 5.387.103.750,86. 
Durante o período estudado constatou-se um acréscimo na receita total de aproximadamente $31,18 \%$. No que diz respeito à participação das esferas, notou-se uma tendência a um aumento da participação da esfera municipal em detrimento das esferas estadual e federal, como pode ser evidenciado no Gráfico 1, resultado que deve ser relativizado pelo fato de que as receitas estaduais geridas pelo próprio estado não constam de nenhum sistema de informação de maneira desagregada o que impede visualizar sua distribuição regional e municipal.

Gráfico 1 - Participação das esferas de gestão na receita dos municípios da Macrorregião Leste do estado da Bahia, entre os anos de 2009 e 2012.

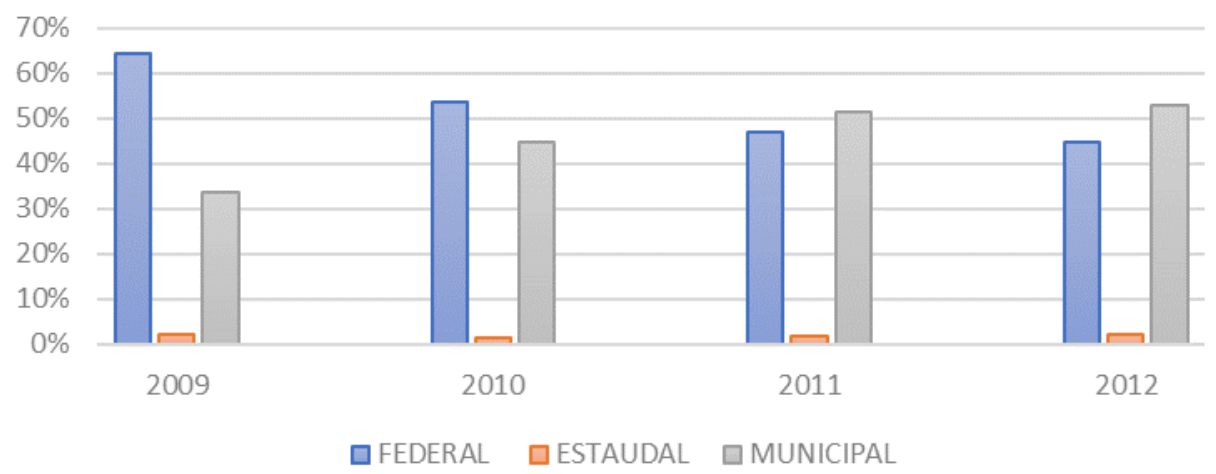

Fonte: Elaboração própria com base nos dados do SIOPS.

Analisando as receitas por habitante percebeu-se que houveram municípios que reduziram e outros que aumentaram sua receita per capita. As reduções mais acentuadas na receita per capita foram encontradas nos municípios de São Sebastião do Passé, com uma redução de 39,46\%, e Dias D’Ávila, com uma redução de 12,78\%. Por outro lado, alguns municípios apresentaram um acentuado aumento na receita per capita, destes destacam-se Muritiba, com 57,99\% de aumento, e Cachoeira, com 49,13\% de aumento na receita per capita. De uma maneira geral, quando se analisa a macrorregião como um todo, a receita por habitante mostrou um aumento médio de $18,91 \%$ no período. Os municípios com maiores receitas foram Camaçari, com uma média de receita de $\mathrm{R} \$$ 105.619.547,06 ao ano, e São Francisco do Conde, com uma média de receita de R\$ 58.334.020,84 ao ano. Por sua vez, os municípios com as menores receitas foram Dom Macedo Costa com uma média de receita de R $\$ 1.580 .392,01$ ao ano e Muniz Ferreira com uma média de receita de $\mathrm{R} \$ 1.815 .377,61$ ao ano.

Observou-se que dois municípios não conseguiram atingir o mínimo proposto pela EC29, esses municípios foram o de Itaparica, o qual apresentou média de 12,02\%, e Salvador, apresentando uma média de $14,44 \%$. Os maus resultados desses municípios não impediram de a macrorregião apresentar um desempenho satisfatório, apresentando uma média de percentual de recursos próprios aplicados em saúde, no período, de $18,42 \%$.

É importante destacar que dois municípios, apesar da obrigatoriedade de prestação de contas, não transmitiram os dados relativos ao gasto com os serviços de saúde. Foram estes: Saubara, no ano de 2012, e Itaparica, no ano de 2011. 


\section{CONSIDERAÇÕES FINAIS (ou Conclusão)}

No presente estudo, contatou-se que, mesmo após passados 29 anos da promulgação da constituição de 1988, a qual previa a descentralização da gestão do SUS, ainda há uma forte participação da esfera Federal, apesar do recente protagonismo da esfera municipal na gestão. Os municípios estudados, mesmo pertencendo à mesma macrorregião, apresentam uma grande heterogeneidade em relação ao gasto per capita, sendo evidente tanto no valor absoluto, quanto na variação que esses valores sofreram ao longo do período estudado. Durante o período estudado, apesar de haverem algumas exceções, houve um aumento nos recursos disponíveis para os municípios, não sendo acompanhada por um aumento proporcional na parcela dos recursos destinados à saúde, a qual apresentou redução. De qualquer forma o estudo gerou questões que instigam investigações mais amplas e devem servir para melhor qualificar a decisão da gestão estadual da saúde na Bahia, como: qual a causa da redução das receitas para a saúde na macrorregião estudada e por que alguns municípios não conseguiram atingir o mínimo proposto pela EC-29?

\section{REFERÊNCIAS}

Médici A. Financiamento público e privado em saúde na América Latina e Caribe: uma breve análise dos anos noventa - Nota Técnica de Saúde, n 3/2005. Brasília: Ministério da Saúde/Banco Interamericano de Desenvolvimento; 2005.

OLIVEIRA, Neilton Araújo. Direito Sanitário: oportuna discussão via coletânea de textos, saúde e cidadania. Brasília: ANVISA, CONASEMS, CONASS, 2012.

COELHO, Thereza Christina Bahia; SCATENA, J. H. G. . Financiamento do SUS. In: Jairnilson Silva Paim; Naomar Almeida-Filho. (Org.). Saúde Coletiva. Teoria e Prática. 1.aed.São Paulo: Medibook, 2013, v. I, p. 600-630.

Conselho Nacional De Secretários De Saúde (CONASS). O Financiamento da Saúde. Brasília: CONASS, 2011. (Coleção "Para entender a gestão do SUS", n. 2) 